\title{
First detection of a Vssc allele V1016G conferring a high level of insecticide resistance in Aedes albopictus collected from Europe (Italy) and Asia (Vietnam), 2016: a new emerging threat to controlling arboviral diseases
}

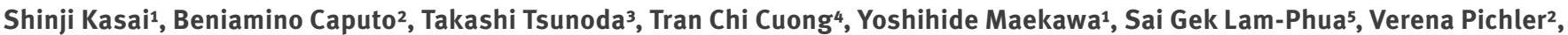
Kentaro Itokawa ${ }^{1,6}$, Katsunori Murota ${ }^{1,6}$, Osamu Komagata ${ }^{1}$, Chigusa Yoshida ${ }^{1}$, Han-Hsuan Chung7, Romeo Bellini ${ }^{8}$, Yoshio Tsuda ${ }^{1}$, Hwa-Jen Teng7, José Luiz de Lima Filho9, Luiz Carlos Alves ${ }^{9,10}$, Lee Ching Ng6 , Noboru Minakawa ${ }^{3}$, Nguyen Thi Yen ${ }^{4}$, Tran Vu Phong ${ }^{4}$, Kyoko Sawabe ${ }^{1}$, Takashi Tomita ${ }^{1}$

1. Department of Medical Entomology, National Institute of Infectious Diseases, Tokyo, Japan

2. Parasitology Unit, Department of Public Health and Infectious Diseases, Università di Roma 'La Sapienza', Rome, Italy

3. Department of Vector Ecology and Environment, Nagasaki University, Nagasaki, Japan

4. Medical Entomology and Zoology Department, National Institute of Hygiene and Epidemiology, Hanoi, Vietnam

5. Environmental Health Institute, National Environment Agency, Singapore

6. Department of Research Promotion, Japan Agency for Medical Research and Development, Tokyo, Japan

7. Center for Diagnostics and Vaccine Development, Centers for Disease Control, Ministry of Health and Welfare, Taiwan

8. Agriculture and Environment Centre "G. Nicoli", Crevalcore, Italy

9. Laboratório de Imunopatologia Keizo Asami, UFPE, Recife, Brazil

10. Aggeu Magalhães Institute, FIOCRUZ, Recife, Brazil

Correspondence: Shinji Kasai (kasacin@nih.go.jp)

Kasai Shinji, Caputo Beniamino, Tsunoda Takashi, Cuong Tran Chi, Maekawa Yoshihide, Lam-Phua Sai Gek, Pichler Verena, Itokawa Kentaro, Murota Katsunori, Komagata Osamu, Yoshida Chigusa, Chung Han-Hsuan, Bellini Romeo, Tsuda Yoshio, Teng Hwa-Jen, Filho José Luiz de Lima, Alves Luiz Carlos, Ng Lee Ching, Minakawa Noboru, Yen Nguyen Thi, Phong Tran Vu, Sawabe Kyoko, Tomita Takashi. First detection of a Vssc allele V1016G conferring a high level of insecticide resistance in Aedes albopictus collected from Europe (Italy) and Asia (Vietnam), 2016: a new emerging threat to controlling arboviral diseases. Euro Surveill. 2019;24(5):pii=1700847. https://doi.org/10.2807/1560-7917.ES.2019.24.5.1700847

Introduction: Aedes albopictus (Skuse) is an important vector of arboviral diseases, including dengue, chikungunya and Zika virus disease. Monitoring insecticide resistance and mechanisms by which the mosquito develops resistance is crucial to minimise disease transmission. Aim: To determine insecticide resistance status and mechanisms in Ae. albopictus from different geographical regions. Methods: We sampled 33 populations of Ae. albopictus from Asia, Europe and South America, and tested these for susceptibility to permethrin, a pyrethroid insecticide. In resistant populations, the target site for pyrethroids, a voltage-sensitive sodium channel (Vssc) was genotyped. Three resistant sub-strains, each harbouring a resistance allele homozygously, were established and susceptibilities to three different pyrethroids (with and without a cytochrome $\mathrm{P} 450$ inhibitor) were assayed. Results: Most populations of Ae. albopictus tested were highly susceptible to permethrin but a few from Italy and Vietnam (4/33), exhibited high-level resistance. Genotyping studies detected a knockdown resistance ( $k d r$ ) allele V1016G in Vssc for the first time in Ae. albopictus. Two previously reported $k d r$ alleles, F1534C and F1534S, were also detected. The bioassays indicated that the strain homozygous for the V1016G allele showed much greater levels of pyrethroid resistance than other strains harbouring F1534C or F1534S.
Conclusion: The V1016G allele was detected in bothAsian and Italian Ae. albopictus populations, thus a spread of this allele beyond Italy in Europe cannot be ruled out. This study emphasises the necessity to frequently and regularly monitor the V1016G allele in Ae. albopictus, particularly where this mosquito species is the main vector of arboviruses.

\section{Introduction}

The Asian tiger mosquito, Aedes albopictus, inhabits tropical and temperate regions and is an important vector of several arboviruses, including dengue, chikungunya and Zika viruses. To minimise the risk of human infection by such viruses, successful control of this mosquito and another important mosquito vector, Aedes aegypti (Linnaeus) is key. Mosquito control stongly relies on the use of insecticides, especially pyrethroids, that are known to have a rapid and high insecticidal activity, but low mammalian toxicity [1].

Insects develop resistance to insecticides by obtaining one or several of three resistance mechanisms: (i) reduced penetration of the insecticide through cuticles, (ii) increased level or activity of detoxification enzyme(s), such as cytochrome P450 monooxygenases (P450s) and carboxyl esterases, and/or (iii) reduced sensitivity of the target site [2]. 
TABLE 1

List of Aedes albopictus populations used for bioassay and genotyping studies, November 2015-March 2017 ( $\mathrm{n}=33$ populations)

\begin{tabular}{|c|c|c|c|c|c|c|}
\hline $\begin{array}{l}\text { Population name } \\
\text { in Figure } 1^{\mathrm{a}}\end{array}$ & Collection site & Code name & Latitude & Longitude & Collection date & $\begin{array}{l}\text { Generation } \\
\text { tested }\end{array}$ \\
\hline Hanoi 1 & Tu Liem, Hanoi, Vietnam & HNI-PK1 & 21.0 & 105.8 & 07-Jun-2016 & $\mathrm{G}_{1}$ \\
\hline Hanoi 2 & Tu Liem, Hanoi, Vietnam & HNI-PK6-9 & 21.0 & 105.8 & 07-Jun-2016 & $\mathrm{G}_{1}$ \\
\hline Hanoi 3 & Tu Liem, Hanoi, Vietnam & HNI-TL6 & 21.0 & 105.8 & 06-Jun-2016 & $\mathrm{G}_{1}$ \\
\hline Hanoi 4 & Tu Liem, Hanoi, Vietnam & $\mathrm{HNI}-\mathrm{TL}_{5}$ & 21.0 & 105.8 & 07-Jun-2016 & $\mathrm{G}_{1}$ \\
\hline Hanoi 5 & Tu Liem, Hanoi, Vietnam & HNI-TL2, 4 & 21.0 & 105.8 & 07-Jun-2016 & $\mathrm{G}_{1}$ \\
\hline Hanoi 6 & Tu Liem, Hanoi, Vietnam & $\mathrm{HNI}-\mathrm{H}_{3}, 5$ & 21.0 & 105.8 & 02-Feb-2016 & $\mathrm{G}_{2}$ \\
\hline Hanoi 7 & Tu Liem, Hanoi, Vietnam & HNI-TL1 & 21.0 & 105.8 & 07-Jun-2016 & $\mathrm{G}_{3}$ \\
\hline Hanoi 8 & Tu Liem, Hanoi, Vietnam & $\mathrm{HNI}-\mathrm{TL}_{3}$ & 21.0 & 105.8 & 07-Jun-2016 & $\mathrm{G}_{3}$ \\
\hline Hanoi 9 & Bat Trang, Hanoi, Vietnam & $\mathrm{HNI}-\mathrm{BT} 2-7$ & 21.0 & 105.9 & 02-Feb-2016 & $\mathrm{G}_{1}$ \\
\hline Bavi 1 & Ba Vi, Hanoi, Vietnam & BAV-3A, 3B & 21.1 & 105.4 & o8-Jun-2016 & $\mathrm{G}_{1}$ \\
\hline Bavi 2 & Ba Vi, Hanoi, Vietnam & BAVI-2A, 2B & 21.1 & 105.4 & 08-Jun-2016 & $\mathrm{G}_{1}$ \\
\hline Bavi 3 & Ba Vi, Hanoi, Vietnam & $\mathrm{BAV}-1 \mathrm{~A}, 1 \mathrm{~B}, 1 \mathrm{C}$ & 21.1 & 105.4 & 08-Jun-2016 & $\mathrm{G}_{1}$ \\
\hline Bavi 4 & Ba Vi, Hanoi, Vietnam & BAV-4A & 21.1 & 105.4 & 08-Jun-2016 & $\mathrm{G}_{1}$ \\
\hline Bavi 5 & Ba Vi, Hanoi, Vietnam & Bavi1-9 & 21.1 & 105.4 & 09-Jun-2016 & $\mathrm{G}_{2}$ \\
\hline Ho Chi Minh 1 & Ho Chi Minh city, Vietnam & HCM-Park1 & 10.8 & 106.7 & 12-Sep-2016 & $\mathrm{G}_{2}$ \\
\hline Ho Chi Minh 2 & Ho Chi Minh city, Vietnam & HCM-Park2, 3 & 10.8 & 106.7 & 16-Sep-2016 & $\mathrm{G}_{1}$ \\
\hline Ho Chi Minh 3 & Ho Chi Minh city, Vietnam & HCM-123-5 & 10.8 & 106.7 & 13-Sep-2016 & $\mathrm{G}_{1}$ \\
\hline Ho Chi Minh 4 & Ho Chi Minh city, Vietnam & HCM-123-1,2,3,4 & 10.8 & 106.7 & 13-Sep-2016 & $\mathrm{G}_{1}$ \\
\hline Ho Chi Minh 5 & Ho Chi Minh city, Vietnam & HCM-108-3,4,9 & 10.8 & 106.7 & 12-Sep-2016 & $\mathrm{G}_{1}$ \\
\hline Cat Tien 1 & $\begin{array}{l}\text { Cat Tien National Park, Dong Nai, } \\
\text { Vietnam }\end{array}$ & $\mathrm{CT}-12,14,17$ & 11.4 & 107.4 & 15-Sep-2016 & G2 \\
\hline Dak Lak 1 & $\begin{array}{c}\text { Yok Don National Park, Dak Lak, } \\
\text { Vietnam }\end{array}$ & DL-P1, 2 & 12.7 & 107.7 & 22-Sep-2016 & $\mathrm{G}_{2}$ \\
\hline Dak Lak 2 & $\begin{array}{c}\text { Yok Don National Park, Dak Lak, } \\
\text { Vietnam }\end{array}$ & DL-F2-10 & 12.7 & 107.7 & 22-Sep-2016 & $\mathrm{G}_{2}$ \\
\hline Dak Lak 3 & Buon Ma Thuot, Dak Lak, Vietnam & DL-U $1-1,2,3,4,5$ & 12.7 & 108.0 & 19-Sep-2016 & $\mathrm{G}_{3}$ \\
\hline Dak Lak 4 & $\begin{array}{c}\text { Yok Don National Park, Dak Lak, } \\
\text { Vietnam }\end{array}$ & $\mathrm{DL}-\mathrm{F} 2-5$ & 12.7 & 107.7 & 22-Sep-2016 & $\mathrm{G}_{3}$ \\
\hline Hoa Kien & Hoa Kien, Phu Yen, Vietnam & Hoa Kien & 13.1 & 109.2 & Nov-2015 & G4 \\
\hline Singapore & Singapore & SP16alb & 1.4 & 103.9 & 2016 & G2 \\
\hline Pingtung & Pingtung city, Taiwan & Pingtung & 22.7 & 120.5 & 08-Mar-2016 & $\mathrm{G}_{2}$ \\
\hline Tainan & Tainan city, Taiwan & Tainan & 23.0 & 120.2 & 03-Mar-2016 & $\mathrm{G}_{2}$ \\
\hline João Pessoa & $\begin{array}{c}\text { João Pessoa, State of Paraíba, } \\
\text { Brazil }\end{array}$ & João Pessoa & -7.1 & -34.8 & 10-Mar-2016 & $\mathrm{G}_{2}$ \\
\hline Maracanã & Maracanã, Rio de Janeiro, Brazil & Maracanã & -22.9 & -43.2 & 13-Mar-2016 & G2 \\
\hline Recife & $\begin{array}{c}\text { Recife, State of Pernambuco, } \\
\text { Brazil }\end{array}$ & RF & -8.1 & -34.9 & Mar-2017 & $\mathrm{G}_{3}$ \\
\hline Emilia Romagna $^{b}$ & $\begin{array}{l}\text { Lido di Spina, Emilia Romagna, } \\
\text { Italy }\end{array}$ & Emilia Romagna & 44.6 & 12.2 & Sep to Oct, 2016 & Go \\
\hline Lazio & Verano, Lazio, Italy & Lazio & 41.9 & 12.5 & Sep to Oct, 2016 & $\mathrm{G}_{1}$ \\
\hline
\end{tabular}

a The Emilia Romagna and Lazio populations are not represented in Figure 1.

${ }^{b}$ Emilia Romagna population was previously used for the bioassay in Pichler et al. [16].

The voltage-sensitive sodium channel (VSSC) is the target site for pyrethroids and dichlorodiphenyltrichloroethane (DDT). It is a membrane protein located on nerve axons, which consists of ca 2,000 amino acid residues. Some amino-acid substitutions in the VSSC are known to confer reduced sensitivity of the channel to pyrethroid insecticides. This type of resistance is generally called knockdown resistance or simply ' $k d r$ ' [3].
In general, Ae. albopictus has been observed to feed on a wide range of hosts and to mainly rest outdoors (exophily) while $A e$. aegypti has a highly anthropophilic (preferring human blood) and endophilic (preferring human domestic environments) behaviours $[4,5]$. Thus, Ae. aegypti might be expected to be more frequently exposed to insecticides, possibly leading to a more rapid selection of resistant alleles in this 


\section{FIGURE 1}

Mortalities of adult Aedes albopictus after exposures to permethrin, September 2015-June 2017 ( $\mathrm{n}=31$ populations)

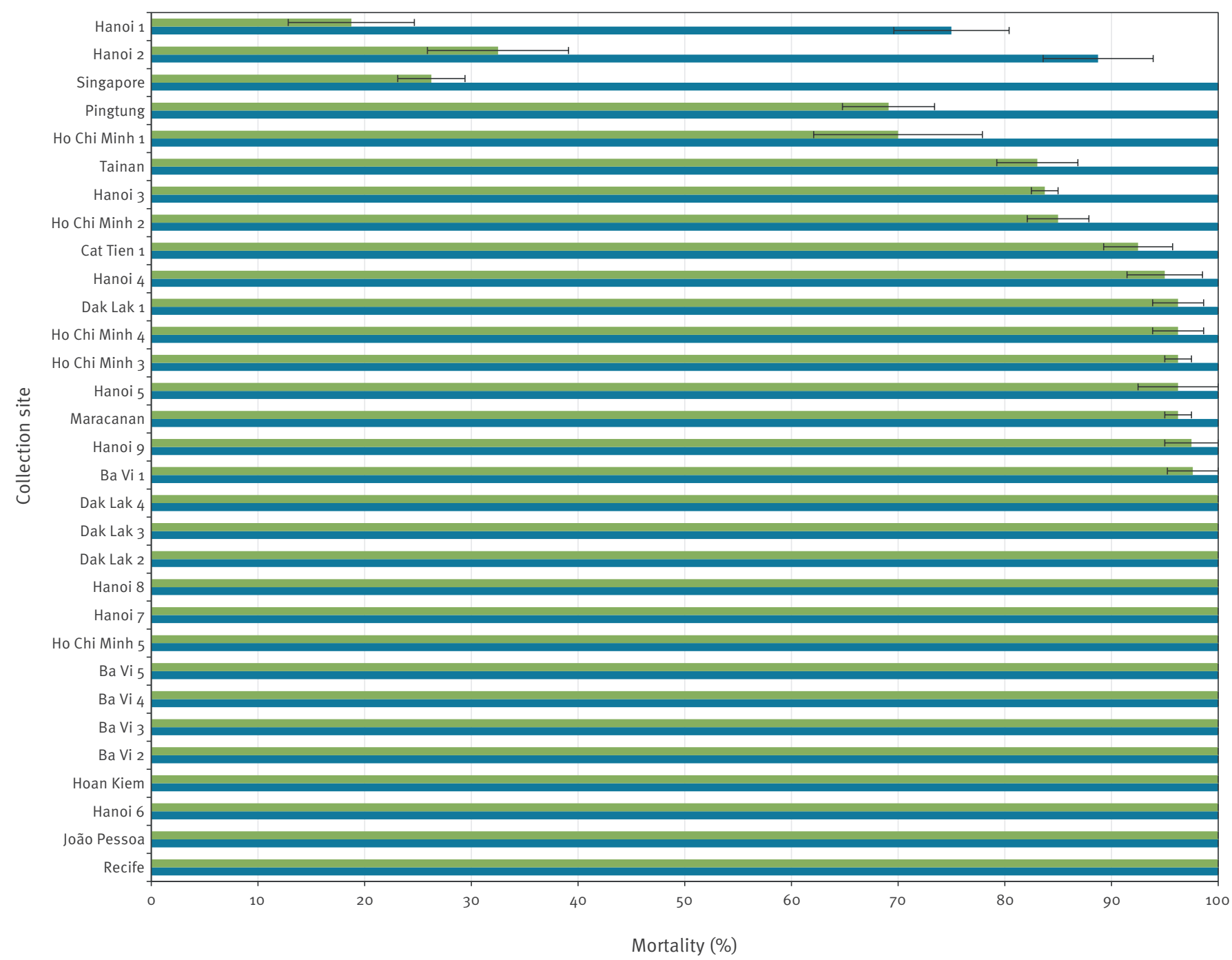

$5.87 \mathrm{ng}$ permethrin/female $\quad 58.7 \mathrm{ng}$ permethrin/female

From each mosquito population, groups of females were topically exposed to two doses of permethrin, i.e. 5.87 ng or 58.7 ng, which were respectively equivalent to the LD99 and LD99x10 doses for the reference strain HKM. Twenty females were simultaneously treated in each assay, whereby the subsequent proportion of dead mosquitoes was calculated. Data, which are presented, are the average of four replicates. Error bars indicate standard errors for the mortalities of each population.

a Data from the Emilia Romagna and Lazio populations are not shown in the Figure as these were obtained by a different method. The bioassay from Pichler et al. [16] was used for the Emilia Romagna population.

species, and the development of higher levels of insecticide resistance compared to Ae. albopictus.

In line with this, several amino-acid substitutions responsible for $k d r$ have been previously reported in Ae. aegypti, either solely or in combination with other substitutions: V1016G; F1534C; S989P+V1016G; $\mathrm{V}_{1016 G}+\mathrm{F}_{1534 C} ; \quad \mathrm{S} 989 \mathrm{P}+\mathrm{V}_{1016} \mathrm{G}+\mathrm{F}_{1534} \mathrm{C}$; $\mathrm{V} 410 \mathrm{~L}+\mathrm{F} 1534 \mathrm{C}[6-8]$.

Pyrethroids can be classified into two groups according to the absence (type I) or presence (type II) of the a-cyano group in their alcohol moiety [1]. Electrophysiological studies have shown that V1016G confers resistance to both type I and II pyrethroids $[9,10]$. This mutation also confers a higher level of resistance than $\mathrm{F} 1534 \mathrm{C}$ to permethrin, a type I pyrethroid, while a VSSC with a ${ }_{1534 C}$ substitution is sensitive to type II pyrethroids, such as deltamethrin and cypermethrin [9-11]. These electrophysiological observations, however, have never been verified by bioassays with strains carrying these alleles homozygously.

In contrast to Ae. aegypti, Ae. albopictus whose behaviour does not primarily depend upon a human living environment, thereby possibly reducing its insecticide exposure, has maintained relatively high susceptibility to pyrethroids [7]. Until 2011, when we 
Genotype of voltage-sensitive sodium channel in seven populations of Aedes albopictus, February 2016-November 2017 ( $\mathrm{n}=293$ mosquitoes)

\begin{tabular}{|c|c|c|c|c|c|c|c|c|c|c|c|c|c|c|}
\hline \multirow{2}{*}{$\begin{array}{l}\text { Genotype } \\
\left(1016-1532-1534^{a}\right)\end{array}$} & \multicolumn{2}{|c|}{$\begin{array}{c}\text { Emilia } \\
\text { Romagna }\end{array}$} & \multicolumn{2}{|c|}{ Lazio } & \multicolumn{2}{|c|}{ Hanoi 1} & \multicolumn{2}{|c|}{ Hanoi 2} & \multicolumn{2}{|c|}{ Ho Chi Minh 1} & \multicolumn{2}{|c|}{ Singapore } & \multicolumn{2}{|c|}{ Pingtung } \\
\hline & Dead $^{b}$ & Alive $^{b}$ & Dead $^{c}$ & Alive $^{c}$ & Dead $^{d}$ & Alive $^{d}$ & Dead $^{\mathrm{e}}$ & Alive $^{\mathrm{e}}$ & Deade $^{\text {e }}$ & Alive $^{\mathrm{e}}$ & Dead $^{\text {e }}$ & Alive $^{e}$ & Deade $^{\text {P }}$ & Alive $^{e}$ \\
\hline $\mathrm{V} / \mathrm{V}-\mathrm{I} / \mathrm{I}-\mathrm{F} / \mathrm{F}$ & 2 & 0 & 0 & 0 & 6 & 0 & 9 & 4 & 17 & 8 & 3 & 0 & 24 & 24 \\
\hline $\mathrm{V} / \mathrm{V}-\mathrm{I} / \mathrm{T}-\mathrm{F} / \mathrm{F}$ & 2 & 1 & 2 & 0 & 0 & 0 & 0 & 0 & 0 & 0 & 0 & 0 & 0 & 0 \\
\hline$V / V-T / T-F / F$ & 3 & 1 & 0 & 0 & 0 & 0 & 0 & 0 & 0 & 0 & 0 & 0 & 0 & 0 \\
\hline $\mathrm{V} / \mathrm{G}-\mathrm{I} / \mathrm{I}-\mathrm{F} / \mathrm{F}$ & 1 & 2 & 1 & 2 & 19 & 0 & 13 & 33 & 0 & 0 & 0 & o & 0 & 0 \\
\hline $\mathrm{V} / \mathrm{G}-\mathrm{I} / \mathrm{T}-\mathrm{F} / \mathrm{F}$ & 2 & 6 & 0 & 2 & 0 & 0 & 0 & 0 & 0 & 0 & 0 & 0 & 0 & 0 \\
\hline $\mathrm{G} / \mathrm{G}-\mathrm{I} / \mathrm{I}-\mathrm{F} / \mathrm{F}$ & 0 & 2 & 0 & 6 & 2 & 20 & 0 & 12 & 0 & 0 & 0 & 0 & 0 & 0 \\
\hline $\mathrm{G} / \mathrm{G}-\mathrm{T} / \mathrm{T}-\mathrm{F} / \mathrm{F}$ & 0 & 0 & 0 & 1 & 0 & 0 & 0 & 0 & 0 & 0 & 0 & o & 0 & 0 \\
\hline $\mathrm{V} / \mathrm{V}-\mathrm{I} / \mathrm{I}-\mathrm{F} / \mathrm{C}$ & 0 & 0 & 0 & 0 & 0 & 0 & 0 & 0 & 7 & 7 & 11 & 9 & 0 & 0 \\
\hline $\mathrm{V} / \mathrm{V}-\mathrm{I} / \mathrm{I}-\mathrm{C} / \mathrm{C}$ & 0 & 0 & 0 & 0 & 0 & 0 & 0 & 0 & 0 & 3 & 6 & 15 & 0 & 0 \\
\hline$V / V-I / I-F / S$ & 0 & 0 & 0 & 0 & 0 & 0 & 1 & 1 & 0 & 0 & 0 & 0 & 0 & 0 \\
\hline $\mathrm{V} / \mathrm{V}-\mathrm{I} / \mathrm{I}-\mathrm{S} / \mathrm{S}$ & 0 & 0 & 0 & 0 & 0 & 0 & 0 & 1 & 0 & 0 & 0 & 0 & 0 & 0 \\
\hline$V / G-I / I-F / S$ & 0 & 0 & 0 & 0 & 0 & 0 & 0 & 2 & 0 & 0 & 0 & 0 & 0 & 0 \\
\hline$n^{f}$ & 10 & 12 & 3 & 11 & 27 & 20 & 23 & 53 & 24 & 18 & 20 & 24 & 24 & 24 \\
\hline$P$ value $^{g}$ for $\mathrm{G}_{1016}$ & \multicolumn{2}{|c|}{0.0245} & \multicolumn{2}{|c|}{0.00658} & \multicolumn{2}{|c|}{$1.84 \times 10^{-10}$} & \multicolumn{2}{|c|}{0.00250} & \multicolumn{2}{|c|}{ NA } & \multicolumn{2}{|c|}{ NA } & \multicolumn{2}{|c|}{ NA } \\
\hline$P$ value $^{\mathrm{g}}$ for T1532 & \multicolumn{2}{|c|}{0.543} & \multicolumn{2}{|c|}{0.459} & \multicolumn{2}{|c|}{ NA } & \multicolumn{2}{|c|}{ NA } & \multicolumn{2}{|c|}{ NA } & \multicolumn{2}{|c|}{ NA } & \multicolumn{2}{|c|}{ NA } \\
\hline$P$ value $^{g}$ for $C_{1534}$ & \multicolumn{2}{|c|}{ NA } & \multicolumn{2}{|c|}{ NA } & \multicolumn{2}{|c|}{ NA } & \multicolumn{2}{|c|}{ NA } & \multicolumn{2}{|c|}{0.0369} & \multicolumn{2}{|c|}{0.0195} & \multicolumn{2}{|c|}{ NA } \\
\hline$P$ value $^{g}$ for $\mathrm{S} 1534$ & \multicolumn{2}{|c|}{ NA } & \multicolumn{2}{|c|}{ NA } & \multicolumn{2}{|c|}{ NA } & 0.6 & & $\mathrm{~N}$ & A & $\mathrm{N}$ & & & A \\
\hline
\end{tabular}

NA: not applicable; WHO: World Health Organization.

${ }^{a}$ Each mosquito has two alleles (maternal and paternal) for each position of the amino acid.

${ }^{\mathrm{b}}$ WHO test (0.75\% permethrin), exposed for $60 \mathrm{~min}$.

c WHO test (0.75\% permethrin), exposed for $15 \mathrm{~min}$.

${ }^{d}$ Topical application (58.7 $\mathrm{ng}$ of permethrin; LD99X10 for HKM).

e Topical application (5.87 ng of permethrin; LD99 for HKM).

${ }^{f} \mathrm{n}$ : Number of females tested.

${ }^{\mathrm{g}}$ Fisher's exact test (number of alleles (wild type or mutated) vs permethrin susceptibility (dead or surviving mosquito)).

reported the detection of $\mathrm{F} 1534 \mathrm{C}$ allele in Ae. albopictus collected from Singapore, no $k d r$ allele had been reported in this particular mosquito species [12]. Subsequently, the same allele was also detected in $A e$. albopictus collected from Greece in 2016 [13] and Brazil in 2017 [14]. In 2016, another possible $k d r$ allele, F1534S, was detected in Ae. albopictus collected from China and the United States $[13,15]$. Levels of pyrethroid resistance conferred by the $\mathrm{F} 1534 \mathrm{~S}$ and $\mathrm{F} 1534 \mathrm{C}$ alleles, however, have never been studied. More recently, Pichler et al. reported first evidence of pyrethroid resistance in Italian Ae. albopictus [16] but the molecular mechanism of the resistance was not investigated.

In the current study, we tested pyrethroid susceptibilities for $33 \mathrm{Ae}$. albopictus populations collected from several geographical regions worldwide and the mechanisms conferring pyrethroid resistance were examined.

\section{Methods}

\section{Collection of mosquitoes}

Larvae of Ae. albopictus were collected from fields of several countries including Brazil, Italy, Vietnam and
Singapore. Mosquitoes were also sampled in Taiwan. Detailed information on populations used for bioassays are listed in Table 1.

Insecticides

Three pyrethroids were used. Two of these, permethrin (91.2\%, Sumitomo Chemical Co., Ltd., Tokyo, Japan) and etofenprox (99.0\%, Wako Pure Chemical Industries, Ltd., Osaka, Japan) were type I pyrethroids. The third, deltamethrin (99.4\%, GL Sciences Inc., Tokyo, Japan), was a type II pyrethoid. Cytochrome P450 inhibitor, piperonyl butoxide (PBO, 98.0\%) was obtained from Wako Pure Chemical Industries, Ltd., Osaka, Japan.

\section{Adult bioassay}

Bioassays were conducted to assess the susceptibility of adult Ae. albopictus to pyrethroids (mated females). Topical applications were performed as described previously [17].

First, bioassays were carried out for a reference strain HKM. The HKM strain was collected originally from Tokyo, Japan in 2010 . The $50 \%$ and $99 \%$ lethal dose $\left(\mathrm{LD}_{50}\right.$ and $\left.\mathrm{LD}_{99}\right)$ values were calculated using Finney's log-probit mortality regression analysis [18], implemented in R version 3.3.3 (www.r-project.org). 
Log dosage-probit mortality lines of six Aedes albopictus strains topically exposed to: (A, B) permethrin, (C, D) etofenprox and (E, F) deltamethrin, September 2015-October $2017(\mathrm{n}=12,145$ mosquitoes)
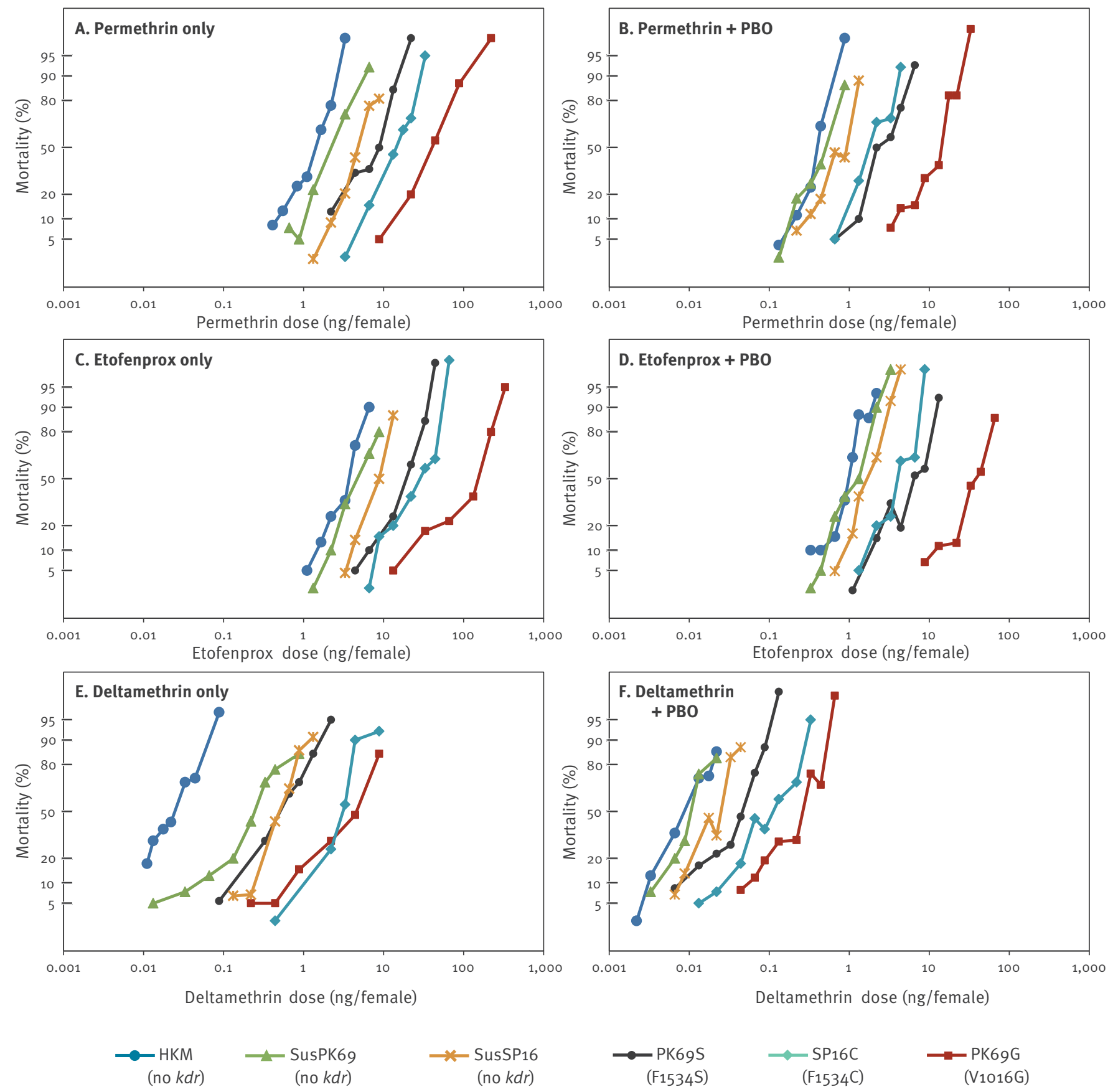

PBO: piperonyl butoxide.

PBO $(2 \mu \mathrm{g})$ was applied 2 hours before the pyrethroid treatment to inhibit detoxification by the detoxification enzyme cytochrome P450s (B, D, F). SusPK69, PK69G and PK69S were isolated from Hanoi 2 population, and SusSP16 and SP16C were isolated from Singapore population. SMK is an insecticide-susceptible strain of Aedes aegypti [17]. 
For testing susceptibilities of field-collected Ae. albopictus populations, treatments were performed with permethrin, $5.87 \mathrm{ng} /$ female (i.e. LD ${ }_{99}$ for HKM) and 58.7 ng/female (i.e. LD $_{99} \times 10$ for HKM) and mortalities were assessed 24 hours after treatments. For every given population, pools of 20 respective mosquitoes ( 4 to 6-days old) were treated in four replicates with each permethrin dose. All bioassays except for two Italian populations were conducted at the National Institute of Infectious Diseases, Japan.

To test the pyrethroid susceptibility of two Italian populations, the World Health Organization (WHO) standard filter paper method [19] containing $0.75 \%$ permethrin was employed as previously described [16] at Sapienza University of Rome. Approximately 25 adult females (3 to 5 -days old) of the Lazio population were exposed in three replicates to the filter paper for $15 \mathrm{~min}$ and mortality was counted 24 hour after the treatment. For the Emilia Romagna population, approximately 25 females ( 3 to 5 -days old) were used in three replicates and permethrin exposure was for $60 \mathrm{~min}$ as previously reported [16]. Permethrin exposure time was shortened for Lazio population to obtain sufficient number of survivors for testing phenotype-genotype association.

\section{Genotyping}

After permethrin bioassays, genomic DNA was extracted from the legs of both dead and surviving mosquitoes using an alkaline method [20]. Partial genomic DNA was sequenced from domains II and III of the Vssc genes from seven populations exhibiting relatively low permethrin susceptibilities: Hanoi 1 ; Hanoi 2; Ho Chi Minh 1; Singapore; Pingtung; Emilia Romagna; and Lazio. Three possible $k d r$ mutation sites reported from Aedes: S989P; V1016G/I; F1534C/S were genotyped by $P C R$ and direct sequencing. Two other mutation sites, I1011M/V [8] and I1532T [13], reported from pyrethroid resistant Ae. aegypti were also investigated. In this paper, we numbered the amino acid position according to the sequence of the most abundant splice variant of the house fly Vssc (GenBank accession number: AAB47604). Detailed procedures for genotyping have been described previously [17], with the exception of our use of the primer AaSCF9 instead of $\mathrm{AaSCF}_{3}$ for sequencing domain II (Supplement S1). For genotyping the $\mathrm{M} 944 \mathrm{~V}$ allele in the alternative exon $D$ [21], females of SusSP16 were exposed to $0.033 \mathrm{ng}$ of deltamethrin and PCR was performed for 31 surviving and eight dead mosquitoes. The albSCF10 and albSCR12 primers were used for PCR and then the PCR products were directly sequenced with albSCF11. The Fisher's exact test was used to assess the significance of the associations between $k d r$ genotype and permethrin susceptibility.

Establishment of homozygous strains

To establish resistant strains harbouring single $k d r$ alleles homozygously, the Hanoi 2 (PK69) and Singapore (SP16) populations were genotyped and each population selectively crossed. Pupae were isolated individually in $2.0 \mathrm{~mL}$ Eppendorf tubes. After these had developed into adults, one hind leg was removed and genomic DNA was isolated. Each mosquito was placed into another 2.0-mL Eppendorf tube with a piece of water-saturated cotton until genotyping analysis was complete. Genotyping was carried out for V1016G and F1534C/S alleles as described above.

For the Hanoi 2 population, 126 virgin females and 71 males were genotyped. Fifteen females and eight males were $\mathrm{V}_{1016 \mathrm{G}}$ allele homozygotes, and we established a sub-strain designated as PK69G from their progenies. Thirty-three females and 22 males, on the contrary, had no $k d r$ alleles. Their progenies were designated as SusPK69.

The Hanoi 2 population also contained the F1534S allele at low frequency. To obtain homozygous individuals, a two-step procedure was employed. First, F1534S/F1534 heterozygotes (11 females and five males) were crossed. In the next generation, mosquitoes with F1534S allele homozygotes (five females and nine males of 128 and 112, respectively) were crossed for establishing PK69S.

For the Singapore population, 140 virgin females and 96 males were genotyped. Eighty-eight females and 59 males which were $\mathrm{F} 1534 \mathrm{C}$ homozygotes were crossed for establishing SP16C sub-strain. Twelve females and eight males with no $k d r$ alleles were also crossed for establishing SusSP16.

Bioassays were carried out to obtain $\mathrm{LD}_{50} \mathrm{~s}$ for isolated strains against permethrin, etofenprox, and deltamethrin as described above. To estimate the contribution of insecticide resistance by P450s, $2 \mu \mathrm{g}$ of PBO, which was a sub-lethal dose for HKM, was applied to mosquitoes 2 hours before exposing with pyrethroids.

Species identification using mitochondria cytochrome c oxidase subunit I gene

Partial mitochondrial cytochrome c oxidase subunit I (COl) genes were sequenced to confirm the mosquito species of six sub-strains (4 individuals from each strain) established in this study (HKM, SusPK69, PK69G, PK69S, SusSP16 and SP16C) as described previously [22].

Next generation sequencing of the Vssc cDNA

Full-length VsSC cDNAs from eight (SusSP16) or four (other strains) virgin females were individually sequenced. RNA was isolated using Isogen II (Nippon Gene Co., Ltd., Tokyo, Japan) and cDNA was synthesised using total RNA, a poly-T primer and an AccuScript High Fidelity 1st Strand cDNA Synthesis Kit (Agilent Technologies, California (CA), United States (US)). Full-length CDNAs of VsSC were amplified by PCR in two overlapping pieces ( $5^{\prime}$ and $3^{\prime}$ ends). For the $5^{\prime}$ end, albSCF1 and albSCR9 primers were used, and for the 3 ' end, albSCF6 and NavAlR22 primers were used 
TABLE 3

Toxicity of three pyrethroids against six strains of Aedes albopictus having different voltage-sensitive sodium channel alleles (PK69G, PK69S, SP16C) or no mutation (HKM, SusPK69, SusSP16), September 2015-October 2017 (n = 12,145 mosquitoes)

\begin{tabular}{|c|c|c|c|c|c|c|c|c|}
\hline Strain & $\mathrm{n}$ & Slope \pm SE & $\mathrm{LD}_{50}(95 \% \mathrm{Cl})$ & $\mathrm{RR}_{1}{ }^{\mathrm{a}}$ & $\mathrm{RR}^{\mathrm{b}}$ & $\mathrm{RR}_{3}{ }^{\mathrm{c}}$ & $\mathrm{SR}^{\mathrm{d}}$ & Ratio of SR (vs HKM) \\
\hline \multicolumn{9}{|c|}{ Permethrin only } \\
\hline HKM & 341 & $3.5 \pm 0.30$ & $1.26(1.13-1.41)$ & 1.0 & NA & NA & NA & NA \\
\hline SusPK69 & 200 & $3.2 \pm 0.35$ & $2.26(1.91-2.66)$ & 1.8 & 1 & NA & NA & NA \\
\hline PK69G & 240 & $2.8 \pm 0.33$ & $39.0(32.5-46.9)$ & 31 & 17 & NA & NA & NA \\
\hline PK69S & 240 & $2.8 \pm 0.35$ & $7.25(6.25-8.41)$ & 5.8 & 3.2 & NA & NA & NA \\
\hline $\mathrm{SP}_{16 C}$ & 200 & $3.1 \pm 0.41$ & $14.4(12.4-16.8)$ & 11 & NA & 2.9 & NA & NA \\
\hline SusSP16 & 303 & $3.8 \pm 0.39$ & $4.92(4.44-5.45)$ & 3.9 & NA & 1 & NA & NA \\
\hline SMKe & 354 & $7.0 \pm 0.65$ & $1.48(1.40-1.56)$ & 1.2 & NA & NA & NA & NA \\
\hline \multicolumn{9}{|c|}{ Permethrin + PBO } \\
\hline HKM & 340 & $4.4 \pm 0.45$ & $0.406(0.366-0.449)$ & 1.0 & NA & NA & 3.1 & 1.0 \\
\hline SusPK69 & 487 & $3.5 \pm 0.28$ & $0.461(0.421-0.506)$ & 1.1 & 1 & NA & 4.9 & 1.6 \\
\hline PK69G & 460 & $3.3 \pm 0.27$ & $11.7(10.6-12.9)$ & 29 & 25 & NA & 2.8 & 0.90 \\
\hline PK69S & 287 & $3.2 \pm 0.36$ & $2.64(2.34-2.98)$ & 6.5 & 5.7 & NA & 2.7 & 0.87 \\
\hline SP16C & 200 & $3.7 \pm 0.40$ & $1.89(1.65-2.15)$ & 4.7 & NA & 2.6 & 7.6 & 2.5 \\
\hline SusSP16 & 311 & $3.5 \pm 0.36$ & $0.735(0.661-0.818)$ & 1.8 & NA & 1 & 6.7 & 2.1 \\
\hline SMK $^{\mathrm{e}}$ & 300 & $5.8 \pm 0.59$ & $0.890(0.835-0.955)$ & 2.2 & NA & NA & 1.7 & 0.55 \\
\hline \multicolumn{9}{|c|}{ Etofenprox only } \\
\hline HKM & 341 & $4.2 \pm 0.34$ & $3.27(2.98-3.58)$ & 1.0 & NA & NA & NA & NA \\
\hline SusPK69 & 200 & $3.4 \pm 0.42$ & $4.85(4.19-5.60)$ & 1.5 & 1 & NA & NA & NA \\
\hline PK69G & 220 & $2.1 \pm 0.27$ & $117(93.6-145)$ & 36 & 24 & NA & NA & NA \\
\hline PK69S & 213 & $3.7 \pm 0.39$ & $16.8(14.6-19.4)$ & 5.1 & 3.5 & NA & NA & NA \\
\hline SP16C & 310 & $3.0 \pm 0.28$ & $25.8(22.7-29.4)$ & 7.9 & NA & 3.3 & NA & NA \\
\hline SusSP16 & 216 & $4.6 \pm 0.49$ & $7.91(7.12-8.78)$ & 2.4 & NA & 1 & NA & NA \\
\hline \multicolumn{9}{|c|}{ Etofenprox + PBO } \\
\hline HKM & 400 & $4.0 \pm 0.34$ & $0.922(0.843-1.01)$ & 1.0 & NA & NA & 3.5 & 1.0 \\
\hline SusPK69 & 280 & $3.8 \pm 0.37$ & $1.11(0.99-1.24)$ & 1.2 & 1.0 & NA & 4.4 & 1.3 \\
\hline PK69G & 508 & $2.9 \pm 0.23$ & $35.8(31.6-40.5)$ & 39 & 32 & NA & 3.3 & 0.94 \\
\hline PK69S & 378 & $2.6 \pm 0.26$ & $5.94(5.16-6.84)$ & 6.4 & 5.4 & NA & 2.8 & 0.80 \\
\hline SP16C & 240 & $3.6 \pm 0.42$ & $4.10(3.65-4.62)$ & 4.4 & NA & 2.4 & 6.3 & 1.8 \\
\hline SusSP16 & 253 & $4.5 \pm 0.45$ & $1.68(1.51-1.86)$ & 1.8 & NA & 1 & 4.7 & 1.3 \\
\hline \multicolumn{9}{|c|}{ Deltamethrin only } \\
\hline HKM & 320 & $2.8 \pm 0.29$ & $0.0230(0.0202-0.0263)$ & 1.0 & NA & NA & NA & NA \\
\hline SusPK69 & 460 & $1.9 \pm 0.19$ & $0.249(0.210-0.296)$ & 11 & 1 & NA & NA & NA \\
\hline PK69G & 240 & $1.9 \pm 0.19$ & $3.22(2.57-4.05)$ & 140 & 13 & NA & NA & NA \\
\hline PK69S & 309 & $2.3 \pm 0.19$ & $0.470(0.389-0.569)$ & 20 & 1.9 & NA & NA & NA \\
\hline SP16C & 220 & $3.4 \pm 0.40$ & $2.80(2.40-3.25)$ & 122 & NA & $5 \cdot 7$ & NA & NA \\
\hline SusSP16 & 221 & $3.3 \pm 0.35$ & $0.492(0.424-0.570)$ & 21 & NA & 1 & NA & NA \\
\hline \multicolumn{9}{|c|}{ Deltamethrin + PBO } \\
\hline HKM & 400 & $2.7 \pm 0.23$ & $0.00917(0.00808-0.0104)$ & 1.0 & NA & NA & 2.5 & 1.0 \\
\hline SusPK69 & 280 & $4.1 \pm 0.39$ & $0.00929(0.00833-0.0103)$ & 1.0 & 1 & NA & 27 & 11 \\
\hline PK69G & 593 & $2.4 \pm 0.18$ & $0.229(0.203-0.258)$ & 25 & 25 & NA & 14 & 5.6 \\
\hline PK69S & 463 & $2.4 \pm 0.19$ & $0.0373(0.0327-0.0425)$ & 4.1 & 4.0 & NA & 13 & 5.2 \\
\hline SP16C & 400 & $2.1 \pm 0.21$ & $0.0969(0.0833-0.113)$ & 11 & NA & 4.3 & 29 & 12 \\
\hline SusSP16 & 417 & $3.4 \pm 0.36$ & $0.0226(0.0207-0.0248)$ & 2.5 & NA & 1 & 22 & 8.8 \\
\hline
\end{tabular}

$\mathrm{Cl}$ : confidence interval; $\mathrm{n}$ : number of mosquitoes tested; NA: not applicable; PBO: piperonyl butoxide; RR: resistance ratio; SE: standard error; SR: synergistic ratio.

${ }^{a} R R 1=L D_{50}$ (each strain) / LD ${ }_{50}(H K M)$.

${ }^{\mathrm{b}} \mathrm{RR} 2=\mathrm{LD}_{50}$ (each strain) / LD ${ }_{50}$ (SusPK69).

${ }^{c} R_{3} 3=L_{50}\left(S_{16} 16\right.$ ) $/ L_{50}$ (SusSP16).

${ }^{\mathrm{d}} \mathrm{SR}=\mathrm{LD}_{50}$ (without $\mathrm{PBO}$ ) / LD ${ }_{50}$ (with $\mathrm{PBO}$ ).

e SMK is an insecticide-susceptible strain of Aedes aegypti [17]. 
(Supplement S1). PCR was performed using PrimeSTAR GXL DNA Polymerase (Takara Bio Inc., Shiga, Japan) under the following conditions: an initial denaturation at $95^{\circ} \mathrm{C}$ for $2 \mathrm{~min}$; followed by 38 cycles at $98^{\circ} \mathrm{C}$ for $10 \mathrm{~S} ; 60^{\circ} \mathrm{C}$ for $15 \mathrm{~S} ; 68^{\circ} \mathrm{C}$ for $3 \mathrm{~min}$; with a final extension at $68^{\circ} \mathrm{C}$ for $10 \mathrm{~min}$. The $5^{\prime}$ - and $3^{\prime}$-cDNA fragments of each mosquito was pooled, sheared, and ligated with same indexed adaptor. After heat inactivating the ligase, all samples of different mosquitoes were pooled, purified with 1XSPRIselect (Beckman Coulter, Brea, CA, US) and fragments of ca 500 to 800 bp DNA were sequenced using the Illumina MiniSeq system (Illumina) in $150 \mathrm{bp}$ paired-end mode using Mini Seq Mid Output kit (Illumina). Illumina data were analysed using the CLC Genomics Workbench ver. 10.0.1 (Qiagen, Venlo, the Netherlands).

\section{Results}

\section{Susceptibility to permethrin of field-collected populations}

At permethrin doses of $5.87 \mathrm{ng} /$ female (i.e. LD $_{99}$ of HKM), 14 of 31 populations exhibited $100 \%$ mortality, nine populations exhibited between $90 \%$ and $100 \%$ mortality and five populations (Hanoi 1, Hanoi 2, Ho Chi Minh 1, Singapore and Pingtung) exhibited $<80 \%$ mortality (Figure 1). When doses were increased to 58.7 $\mathrm{ng} /$ female, all populations, except two from Vietnam, exhibited $100 \%$ mortality. Hanoi 1 and Hanoi 2 populations showed mortalities of $75.0 \%$ and $88.8 \%$, respectively, under the higher dose.

Lazio population exhibited $77.1 \% \pm 7.5 \%$ mortality by WHO filter paper method. As was previously reported, Emilia Romagna population exhibited $81.3 \% \pm 15 \%$ mortality [16]. According to WHO guidelines, populations were considered 'resistant' if mortality was $<90 \%$ upon pyrethroid exposure for $60 \mathrm{~min}[16]$.

\section{Genotyping of Vssc}

Partial genomic DNA fragments of Vssc were sequenced from the seven populations that showed relatively low susceptibilities to permethrin. Genotypes and frequencies of Vssc alleles are shown in Table 2. Genotyping results are deposited to VectorBase.org (Project ID: VBPooo0370). The V1016G allele was detected in four populations: Emilia Romagna and Lazio (both Italy); Hanoi 1 and Hanoi 2 (both Vietnam). This was the first detection of the $\mathrm{V}_{1016 \mathrm{G}}$ allele from Ae. albopictus. In all populations, frequencies of the $\mathrm{V}_{1016 \mathrm{G}}$ allele were higher in surviving animals than in dead ones and the genotype $\mathrm{G}_{1016}$ showed significant association ( $p<0.01)$ to permethrin resistance in all Lazio, Hanoi 1 , and Hanoi 2 populations (Table 2). All survivors of Hanoi 1 population exposed to permethrin of $L_{99} \mathrm{X}_{10}$ were homozygous for the $\mathrm{V}_{1016 G}$ allele.

The $\mathrm{F} 1534 \mathrm{C}$ allele was detected in the Ho Chi Minh 1 and Singapore populations. The genotype C1534 showed weak associations to permethrin resistance in Ho Chi Minh 1 and Singapore populations $(p=0.0369$ and 0.0195 , respectively) (Table 2 ). The F1534S allele was detected in the Hanoi 2 population in the current study as well. There is so far no evidence of a double mutation $\mathrm{V}_{1016} \mathrm{G}+\mathrm{F}_{1534 \mathrm{~S}}$. Other possible $k d r$ alleles S989P or l1011M were not detected in this study. We also did not detect the L1014F allele, which is the most common $k d r$ mutation found in many insects but has never been detected from Aedes mosquitoes so far [8].

\section{Establishment of homozygous strains}

Five sub-strains were established in this study. The PK69G, PK69S and SusPK69 sub-strains were isolated from the Hanoi 2 population (originally designated as PK69), while the SP16C and SusSP16 sub-strains were isolated from the Singapore population (originally designated as SP16). The $\mathrm{COI}$ analysis revealed that all sequences showed the highest homology scores to Ae. albopictus genes using Nt Basic Local Alignment Search Tool (BLAST) search (data not shown).

Genotyping of 24 mosquitoes from each sub-strain confirmed that PK69G, PK69S and SP16C possess the V1016G, F1534S, or F1534C alleles, respectively and homozygously.

\section{Contribution of each $k d r$ allele to pyrethroid resistance}

We carried out bioassays with three pyrethroids (i.e. deltamethrin, etofenprox and permethrin) against HKM and the five established sub-strains (PK69G, PK69S, SusPK69, SP16C and SusSP16). Dose-probit mortality lines are shown in Figure 2. Slopes, $L D_{50} \mathrm{~S}$, resistance ratios and the synergistic ratios of PBO are shown in Table 3. The $\mathrm{LD}_{50}$ of HKM to permethrin was $1.26 \mathrm{ng} /$ female which was lower than the $\mathrm{LD}_{50}$ of SMK (1.48 $\mathrm{ng} /$ female), an insecticide susceptible strain of $A e$. aegypti (Table 3) [17].

When we assayed only for pyrethroid resistance, PK69G exhibited the highest resistance level of all of the six strains to all three pyrethroids. PK69G and SP16C exhibited particularly high levels of resistance to deltamethrin; resistance ratios were $140-$ and 122 -fold, respectively, compared with the HKM strain. SusPK69 and SusSP16, neither of which possesses $k d r$ alleles, also showed resistance ratios to deltamethrin of 11- and 21-fold, respectively, compared with the HKM strain.

Synergistic ratios of PBO on deltamethrin toxicity were 11- and 8.8-fold higher in the SusPK69 and SusSP16 strains, respectively than HKM.

Resistance ratios (pyrethroids + PBO) in PK69G and PK69S were 25- to 32-fold and 4.0- to 5.7-fold, respectively compared with the SusPK69 strain. In SP16C strain, resistance ratios (pyrethroids + PBO) were 2.4to 4.3 -fold compared with the SusSP16 strain (Table 3). Therefore, the strain harbouring V1016G allele (PK69G) showed several fold higher resistance levels than the strains harbouring $\mathrm{F}_{1534 \mathrm{~S}}$ allele (PK69S) or F1534C allele (SP16C). 
TABLE 4

Mutations found in full length voltage-sensitive sodium channel protein in six strains of Aedes albopictus, June 2017-

October 2017 ( $\mathrm{n}=28$ mosquitoes)

\begin{tabular}{|c|c|c|c|c|c|c|c|c|c|}
\hline \multirow{2}{*}{$\begin{array}{l}\text { Individual } \\
\text { number }\end{array}$} & \multicolumn{9}{|c|}{ Mutations } \\
\hline & $\mathrm{K}_{427 \mathrm{R}}$ & M686I & $\mathrm{E} 832 \mathrm{D}$ & $\begin{array}{c}\text { M944V (Exon } \\
\mathrm{Da})\end{array}$ & V1016G & $\mathrm{F} 1534 \mathrm{C} / \mathrm{S}$ & $\mathrm{T} 2002 \mathrm{P}$ & A2023T & G2054GGG \\
\hline \multicolumn{10}{|c|}{ HKM (susceptible strain) } \\
\hline$\# 1$ & $K / R$ & $M / M$ & $E / E$ & $M / M$ & $\mathrm{~V} / \mathrm{V}$ & $F / F$ & $T / T$ & $\mathrm{~A} / \mathrm{A}$ & $\mathrm{G} / \mathrm{G}$ \\
\hline$\# 2$ & $\mathrm{~K} / \mathrm{R}$ & $\mathrm{M} / \mathrm{M}$ & $E / E$ & $M / M$ & $\mathrm{~V} / \mathrm{V}$ & $\mathrm{F} / \mathrm{F}$ & $T / T$ & $\mathrm{~A} / \mathrm{A}$ & G/GGG \\
\hline \#3 & $K / R$ & $M / M$ & $E / E$ & $\mathrm{M} / \mathrm{M}$ & $\mathrm{V} / \mathrm{V}$ & $\mathrm{F} / \mathrm{F}$ & $\mathrm{T} / \mathrm{T}$ & $\mathrm{A} / \mathrm{A}$ & $\mathrm{G} / \mathrm{G}$ \\
\hline \#4 & $K / R$ & $M / I$ & $E / E$ & $M / M$ & $\mathrm{~V} / \mathrm{V}$ & $F / F$ & $T / T$ & $A / A$ & G/GGG \\
\hline \multicolumn{10}{|c|}{ SusPK69 (PK69 having no kdr mutation) } \\
\hline$\# 1$ & $\mathrm{~K} / \mathrm{R}$ & $M / M$ & $E / E$ & $M / M$ & $\mathrm{~V} / \mathrm{V}$ & $\mathrm{F} / \mathrm{F}$ & $T / T$ & $\mathrm{~A} / \mathrm{A}$ & $\mathrm{G} / \mathrm{G}$ \\
\hline$\# 2$ & $\mathrm{~K} / \mathrm{R}$ & $\mathrm{M} / \mathrm{M}$ & $E / E$ & $\mathrm{M} / \mathrm{M}$ & $\mathrm{V} / \mathrm{V}$ & $\mathrm{F} / \mathrm{F}$ & $\mathrm{T} / \mathrm{P}$ & $\mathrm{A} / \mathrm{A}$ & $\mathrm{G} / \mathrm{G}$ \\
\hline \#3 & $\mathrm{K} / \mathrm{R}$ & $M / M$ & $E / E$ & $M / M$ & $\mathrm{~V} / \mathrm{V}$ & $\mathrm{F} / \mathrm{F}$ & $T / T$ & $\mathrm{~A} / \mathrm{A}$ & $\mathrm{G} / \mathrm{G}$ \\
\hline \#4 & $\mathrm{K} / \mathrm{R}$ & $\mathrm{M} / \mathrm{M}$ & $E / E$ & $M / M$ & $\mathrm{~V} / \mathrm{V}$ & $\mathrm{F} / \mathrm{F}$ & $T / T$ & $\mathrm{~A} / \mathrm{A}$ & G/G \\
\hline \multicolumn{10}{|c|}{ PK69G (PK69 having V1016G mutation) } \\
\hline$\# 1$ & $\mathrm{~K} / \mathrm{R}$ & $M / M$ & $E / E$ & $M / M$ & $\mathrm{G} / \mathrm{G}$ & $\mathrm{F} / \mathrm{F}$ & $T / T$ & $\mathrm{~A} / \mathrm{A}$ & G/GGG \\
\hline \#2 & $K / R$ & $M / M$ & $E / E$ & $\mathrm{M} / \mathrm{M}$ & $\mathrm{G} / \mathrm{G}$ & $\mathrm{F} / \mathrm{F}$ & $\mathrm{T} / \mathrm{T}$ & $A / A$ & $\mathrm{G} / \mathrm{G}$ \\
\hline \#3 & $K / R$ & $M / M$ & $E / E$ & $\mathrm{M} / \mathrm{M}$ & $\mathrm{G} / \mathrm{G}$ & $\mathrm{F} / \mathrm{F}$ & $T / T$ & $\mathrm{~A} / \mathrm{A}$ & G/GGG \\
\hline \#4 & $K / R$ & $M / M$ & $E / E$ & $M / M$ & $\mathrm{G} / \mathrm{G}$ & $\mathrm{F} / \mathrm{F}$ & $\mathrm{T} / \mathrm{T}$ & $\mathrm{A} / \mathrm{A}$ & $\mathrm{G} / \mathrm{G}$ \\
\hline \multicolumn{10}{|c|}{ PK69S (PK69 having F1534S mutation) } \\
\hline \#1 & $K / R$ & $M / M$ & $E / E$ & $M / M$ & $\mathrm{~V} / \mathrm{V}$ & $\mathrm{S} / \mathrm{S}$ & $T / T$ & $\mathrm{~A} / \mathrm{T}$ & $\mathrm{G} / \mathrm{G}$ \\
\hline \#2 & $K / R$ & $M / M$ & $E / E$ & $M / M$ & $\mathrm{~V} / \mathrm{V}$ & $\mathrm{S} / \mathrm{S}$ & $T / T$ & $A / T$ & $\mathrm{G} / \mathrm{G}$ \\
\hline \#3 & $\mathrm{K} / \mathrm{R}$ & $M / M$ & $E / E$ & $M / M$ & $\mathrm{~V} / \mathrm{V}$ & $\mathrm{S} / \mathrm{S}$ & $T / T$ & $A / T$ & $\mathrm{G} / \mathrm{G}$ \\
\hline \#4 & $\mathrm{K} / \mathrm{R}$ & $M / M$ & $E / E$ & $M / M$ & $\mathrm{~V} / \mathrm{V}$ & $\mathrm{S} / \mathrm{S}$ & $T / T$ & $A / T$ & G/G \\
\hline \multicolumn{10}{|c|}{ SusSP16 (SP16 having no $k d r$ mutation) } \\
\hline$\# 1$ & $K / R$ & $M / M$ & $E / E$ & $\mathrm{~V} / \mathrm{V}$ & $\mathrm{V} / \mathrm{V}$ & $\mathrm{F} / \mathrm{F}$ & $\mathrm{T} / \mathrm{T}$ & $\mathrm{A} / \mathrm{A}$ & $\mathrm{G} / \mathrm{G}$ \\
\hline$\# 2$ & $K / R$ & $M / M$ & $E / E$ & $M / V$ & $\mathrm{~V} / \mathrm{V}$ & $\mathrm{F} / \mathrm{F}$ & $\mathrm{T} / \mathrm{T}$ & $\mathrm{A} / \mathrm{A}$ & $\mathrm{G} / \mathrm{G}$ \\
\hline \#3 & $\mathrm{K} / \mathrm{R}$ & $\mathrm{M} / \mathrm{M}$ & $E / D$ & $\mathrm{M} / \mathrm{V}$ & $\mathrm{V} / \mathrm{V}$ & $\mathrm{F} / \mathrm{F}$ & $T / T$ & $\mathrm{~A} / \mathrm{A}$ & $\mathrm{G} / \mathrm{G}$ \\
\hline \#4 & $\mathrm{K} / \mathrm{R}$ & $M / M$ & $E / D$ & $M / M$ & $\mathrm{~V} / \mathrm{V}$ & $\mathrm{F} / \mathrm{F}$ & $T / T$ & $\mathrm{~A} / \mathrm{A}$ & $\mathrm{G} / \mathrm{G}$ \\
\hline \#5 & $K / R$ & $M / M$ & $E / E$ & $\mathrm{~V} / \mathrm{V}$ & $\mathrm{V} / \mathrm{V}$ & $\mathrm{F} / \mathrm{F}$ & $T / T$ & $A / A$ & $\mathrm{G} / \mathrm{G}$ \\
\hline \#6 & $K / R$ & $M / M$ & $E / E$ & $\mathrm{M} / \mathrm{V}$ & $\mathrm{V} / \mathrm{V}$ & $\mathrm{F} / \mathrm{F}$ & $\mathrm{T} / \mathrm{T}$ & $\mathrm{A} / \mathrm{A}$ & $\mathrm{G} / \mathrm{G}$ \\
\hline \#7 & $K / R$ & $M / M$ & $E / E$ & $M / V$ & $\mathrm{~V} / \mathrm{V}$ & $\mathrm{F} / \mathrm{F}$ & $T / T$ & $A / A$ & $\mathrm{G} / \mathrm{G}$ \\
\hline$\# 8$ & $\mathrm{~K} / \mathrm{R}$ & $M / M$ & $E / E$ & $\mathrm{~V} / \mathrm{V}$ & $\mathrm{V} / \mathrm{V}$ & $\mathrm{F} / \mathrm{F}$ & $T / T$ & $\mathrm{~A} / \mathrm{A}$ & $\mathrm{G} / \mathrm{G}$ \\
\hline \multicolumn{10}{|c|}{ SP16C (SP16 having F1534C mutation) } \\
\hline$\# 1$ & $K / R$ & $M / M$ & $E / E$ & $\mathrm{M} / \mathrm{V}$ & $\mathrm{V} / \mathrm{V}$ & $\mathrm{C} / \mathrm{C}$ & $\mathrm{T} / \mathrm{T}$ & $A / T$ & $\mathrm{G} / \mathrm{G}$ \\
\hline$\# 2$ & $\mathrm{~K} / \mathrm{R}$ & $\mathrm{M} / \mathrm{M}$ & $\mathrm{E} / \mathrm{E}$ & $\mathrm{M} / \mathrm{M}$ & $\mathrm{V} / \mathrm{V}$ & $\mathrm{C} / \mathrm{C}$ & $T / T$ & $A / T$ & $\mathrm{G} / \mathrm{G}$ \\
\hline$\# 3$ & $\mathrm{~K} / \mathrm{R}$ & $M / M$ & $E / E$ & $\mathrm{M} / \mathrm{M}$ & $\mathrm{V} / \mathrm{V}$ & $\mathrm{C} / \mathrm{C}$ & $T / T$ & $\mathrm{~A} / \mathrm{T}$ & $\mathrm{G} / \mathrm{G}$ \\
\hline \#4 & $\mathrm{K} / \mathrm{R}$ & $\mathrm{M} / \mathrm{M}$ & $E / E$ & $\mathrm{M} / \mathrm{M}$ & $\mathrm{V} / \mathrm{V}$ & $\mathrm{C} / \mathrm{C}$ & $T / T$ & $A / T$ & $\mathrm{G} / \mathrm{G}$ \\
\hline
\end{tabular}

a Alternatively spliced exon D as designated in the previous study [21].

Other amino acid changes

Full length Vssc cDNAs were individually sequenced using Illumina MiniSeq NGS (Table 4). Results were submitted to Sequence Read Archive, SRA (BioProject ID: PRJDB6889). All 12 mosquitoes of PK69G, PK69S and SP16C possessed the $\mathrm{V}_{1016 \mathrm{G}}$, F1534S, or F1534C alleles, respectively and homozygously. In contrast, HKM, SusPK69 and SusSP16 did not have any alleles at these three amino acid loci. On the other hand, M686I, E832D and M944V (in the alternative exon D [21]) alleles were detected from HKM and SusSP16 strains. Since $\mathrm{M} 944 \mathrm{~V}$ was detected at a relatively high frequency in the SusSP16 strain, we genotyped this allele for both dead and surviving mosquitoes after deltamethrin (+ PBO) selection. The frequency of M944V allele in dead and surviving insects was 33/62 and 10/16, respectively, and there was no statistically significant difference observed between these two populations $(p=0.581)$.

In addition, the $\mathrm{T}_{2002 \mathrm{P}}$ and $\mathrm{A}_{2023} \mathrm{~T}$ alleles and an insertion of double glycine, were detected from the HKM, SusPK69, PK69S, SP16C and PK69G strains, all heterozygously. The E832D allele was detected in two of eight mosquitoes heterozygously in SusSP16. The 
K 427R allele was detected heterozygously from all 28 mosquito samples tested.

\section{Discussion}

Only two $k d r$ alleles, F1534C and F1534S, have been reported from Ae. albopictus to date. In this study, a stronger kdrallele, V1016G, was detected in four Ae. albopictus populations collected from Italy and Vietnam, and its frequency was highly correlated with pyrethroid resistance. Thus, the present data are the first evidence of the $\mathrm{V}_{1016 G}$ allele from this mosquito species. It is speculated that $\mathrm{V}_{1016 \mathrm{G}}$ allele was associated with the recent detection of pyrethroid resistant $A e$. albopictus from Italy [16]. Previous electrophysiological studies have indicated that the V1016G allele in VSSC resulted in lower sensitivities to pyrethroids than $\mathrm{F}_{1534 \mathrm{C}}$ [9-11], even though this was never evidenced in bioassays with living, homozygous strains. In this study, we established three new resistant sub-strains, each homozygously harbouring the V1016G, F1534C and F1534S alleles. Bioassays using PBO revealed that the $\mathrm{V}_{1016} \mathrm{G}$ allele was associated with greater pyrethroid resistance than the $\mathrm{F} 1534 \mathrm{C}$ and the F1534S, which supports previous electrophysiological studies [9-11].

We also detected the $1532 \mathrm{~T}$ allele from the Emilia Romagna and Lazio populations, as previously reported [13]. There was, however, no association between this allele and permethrin susceptibility ( $p>0.4$, Table 2 ). In addition, T2002P and $\mathrm{A} 2023 \mathrm{~T}$ alleles were newly found. These mutations, however, are unlikely to confer pyrethroid resistance since they are located near the C-terminus of the VSSC, where a polymorphic region is common among insect species. Curiously, the $\mathrm{K}_{42} 27 \mathrm{R}$ allele was detected from all 28 mosquito samples tested by next generation sequencing. At this point we cannot provide any concrete explanation for this observation. One possible reason is RNA editing, as has been reported in previous studies on insect sodium channels [23]. The SusPK69 and SusSP16 strains, both of which have no $k d r$ allele, showed 11- and 8.8folds higher synergistic ratio on deltamethrin toxicity than that of HKM strain suggesting that $\mathrm{P} 450$ was certainly involved in the resistance in both the Hanoi 2 and Singapore populations. The Pingtung population showed a relatively lower susceptibility to permethrin, however, we did not detect any $k d r$ allele within the VsSC regions sequenced, indicating the possibility of unknown $k d r$ mutation or another resistance mechanism.

In this study, the VsSC harbouring the V1016G allele was not detected from Ae. albopictus collected outside of Hanoi City in Vietnam. As shown by our bioassay results, most of the populations collected in Vietnam, other than Hanoi 1 and Hanoi 2, exhibited high susceptibilities to permethrin, with the exception of one population from Ho Chi Minh City that included only a weak $k d r \mathrm{~F} 1534 \mathrm{C}$ at a relatively low frequency. Therefore, there is no evidence that the $\mathrm{V}_{1016 \mathrm{G}}$ allele has spread widely in Asia. If that is the case, this raises several questions: (i) Why was this rare allele detected in mosquitoes collected from Italy?; and (ii) when and how was such a mosquito introduced into this country? It has been speculated that the origin of $A e$. albopictus is south-east Asia, and that its distribution area spreads across Asia and into Europe via various imported items, such as used tyres and plant pods $[24,25]$. After the first chikungunya endemic in 2007 [26], pyrethroids have been frequently used for controlling adult Aedes mosquitoes in Italy [27]. It is possible that a very small number of mosquitoes with the $V_{1016 G}$ allele were included in the initial population(s) of Italy and were gradually selected by pyrethroids, such that the allele frequency finally reached a level to which it could confer resistance. On the other hand, we cannot exclude the possibility that $\mathrm{V}_{1016 \mathrm{G}}$ mutation occurred independently in Italy and Vietnam. In any case, the fact that the V1016G allele was detected in both northern (Emilia Romagna) and central (Lazio) Italy suggests, at least, that the introduction or appearance of this allele into the country occurred some time ago. It is further possible that $A e$. albopictus mosquitoes harbouring the V1016G allele have spread already to other European countries; we therefore, emphasise the necessity to monitor this $k d r$ allele in Ae. albopictus populations throughout Europe and other regions inhabited by $A e$. albopictus. Furthermore, it is known that additional amino acid substitution can synergistically enhance effect of a $k d r$ mutation $[28,29]$. An electrophysiological study has revealed that triple mutations of S989P, V1016G and F1534C in VSSC confer much greater levels of pyrethroid insensitivity than each single mutation [9] and $A e$. aegypti mosquitoes harbouring these alleles actually have been found in several Asian countries [7]. The possibility exists that double or triple mutations including V1016G and another (other) $k d r$ mutation(s) could also emerge in Ae. albopictus.

Recently, in chikungunya virus from the Indian Ocean, an alanine to valine mutation was found at position 226 in the E1 envelope glycoprotein, which caused a more than 100-fold increase in the vector competence of $A e$. albopictus for this virus variant [30]. Autochthonous dengue outbreaks in Croatia (2010), Japan (2014), China (2014) and France (2015) were vectored by Ae. albopictus [31-34] and demonstrated the importance of this mosquito species for arbovirus transmission.

Development of insecticide resistance in Ae. albopictus had not been noted until recently, though the problem in Ae. aegypti has been well established and has become a priority concern in many countries $[6,7]$. However, since a strong $k d r$ allele $\mathrm{V}_{1016 \mathrm{G}}$ has been detected in Ae. albopictus, resistance in this species should also be considered. With the increased use of pyrethroids, the high level of insecticide resistance could potentially become widespread. Actions to prevent or delay this therefore need to be taken. 
Multiple electrophysiological studies have suggested that the F1534C allele confers resistance to type I pyrethroids, but not to type II pyrethroids [9-11]. In this study, the SP16C strain harbouring the F1534C allele exhibited resistance not only to the type I pyrethroid permethrin (+ PBO) but also $4 \cdot 3$-fold of resistance to the type II pyrethroid deltamethrin (+PBO), compared with the SusSP16 strain. It is suspected that this was simply due to the $\mathrm{F}_{1534} \mathrm{C}$ allele, because SP16C and SusSP16 strains were isolated from the same Singapore population and are supposed to share a similar genetic background. So, this result may suggest that $\mathrm{F} 1534 \mathrm{C}$ confers resistance to type II pyrethroids as well. At this point, on the other hand, we cannot completely exclude the possibility that the effect was also due to another mutation hitchhiking near Vssc gene. A further study is needed to confirm this. Use of a congenic strain, which is established by backcrossing a $k d r$-type strain with a susceptible strain for several generations, may help to answer this question [35].

In conclusion, we report here for the first time detection of a VsSC allele, V1016G, in the mosquito Ae. albopictus. This allele was detected not only in $A e$. albopictus collected from Asia (Vietnam), but also from Europe (Italy). In our study the V1016G allele conferred a higher level of pyrethroid resistance than the previously known alleles, F1534C and F1534S. As this could be relevant for the control of $A e$. albopictus, we highlight the importance of monitoring this allele, especially in temperate regions where this insect species is the major vector of arboviral pathogens.

\section{Acknowledgements}

This research was partially supported by the Research Program on Emerging and Re-emerging Infectious Diseases from Japan Agency for Medical Research and development (AMED) and by Japan Initiative for Global Research Network on Infectious Diseases (J-GRID) from Ministry of Education, Culture, Sports, Science and Technology in Japan and AMED. The authors would like to thank Enago (www.enago.jp) for the English language review.

\section{Conflict of interest}

None declared.

\section{Authors' contributions}

SK, BC, KI, OK, TaTo, NM, KS designed the study. SK, BC, TaTs, TCC, YM, SGLP, VP, KI, KM, HHC, YT, HJT, LCN, NTY, TVP, KS, JLLF, LCA, RB collected mosquito larvae. SK, BC, VP, CY reared mosquitoes and carried out bioassays. SK, CY did genotyping studies and established strains. SK and KI took part in Illumina MiniSeq sequencing and computer analysis. SK drafted the manuscript. All authors critically revised the manuscript and approved for publication.

\section{References}

1. Shono T. Pyrethroid resistance: Importance of the kdr-type mechanism. J Pestic Sci. 1985;10(1):141-6. https://doi. org/10.1584/jpestics.10.141

2. Georghiou GP, Saito T. Pest Resistance to Pesticides. Plenum Press; 1983.

3. Milani R. Mendelian behaviour of resistance to the knockdown action of DDT and correlation between knockdown and mortality in M. domestica L. Riv Parassitol. 1954;15:513-43.

4. Lok C. Singapore's dengue haemorrhagic fever control programme: A case study on the successful control of Aedes aegypti and Aedes albopictus using mainly environmental measures as a part of integrated vector control. Tokyo: Southeast Asian Medical Information Center; 1985. 114 p.

5. Gubler DJ, Kuno G. Dengue and dengue hemorrhagic fever. Cambridge: University Press; 1997.

6. Moyes CL, Vontas J, Martins AJ, Ng LC, Koou SY, Dusfour I, et al. Contemporary status of insecticide resistance in the major Aedes vectors of arboviruses infecting humans. PLoS Negl Trop Dis. 2017;11(7):e0005625. https://doi.org/10.1371/journal. pntd.0005625 PMID: 28727779

7. Smith LB, Kasai S, Scott JG. Pyrethroid resistance in Aedes aegypti and Aedes albopictus: Important mosquito vectors of human diseases. Pestic Biochem Physiol. 2016;133:1-12. https://doi.org/10.1016/j.pestbp.2016.03.005 PMID: 27742355

8. Rinkevich FD, Du Y, Dong K. Diversity and convergence of sodium channel mutations involved in resistance to pyrethroids. Pestic Biochem Physiol. 2013;106(3):93-100. https://doi.org/10.1016/j.pestbp.2013.02.007 PMID: 24019556

9. Hirata K, Komagata O, Itokawa K, Yamamoto A, Tomita T, Kasai S. A single crossing-over event in voltage-sensitive $\mathrm{Na}+$ channel genes may cause critical failure of dengue mosquito control by insecticides. PLoS Negl Trop Dis. 2014;8(8):e3085. https://doi.org/10.1371/journal.pntd.0003085 PMID: 25166902

10. Du Y, Nomura Y, Satar G, Hu Z, Nauen R, He SY, et al. Molecular evidence for dual pyrethroid-receptor sites on a mosquito sodium channel. Proc Natl Acad Sci USA. 2013;110(29):1178590. https://doi.org/10.1073/pnas.1305118110 PMID: 23821746

11. Hu Z, Du Y, Nomura Y, Dong K. A sodium channel mutation identified in Aedes aegypti selectively reduces cockroach sodium channel sensitivity to type I, but not type II pyrethroids. Insect Biochem Mol Biol. 2011;41(1):9-13. https:// doi.org/10.1016/j.ibmb.2010.09.005 PMID: 20869441

12. Kasai S, Ng LC, Lam-Phua SG, Tang CS, Itokawa K, Komagata 0 , et al. First detection of a putative knockdown resistance gene in major mosquito vector, Aedes albopictus. Jpn J Infect Dis. 2011;64(3):217-21. PMID: 21617306

13. Xu J, Bonizzoni M, Zhong D, Zhou G, Cai S, Li Y, et al. Multicountry survey revealed prevalent and novel F1534S mutation in voltage-gated sodium channel (VGSC) gene in Aedes albopictus. PLoS Negl Trop Dis. 2016;10(5):eo004696. https:// doi.org/10.1371/journal.pntd.0004696 PMID: 27144981

14. Aguirre-Obando OA, Martins AJ, Navarro-Silva MA. First report of the Phe1534Cys kdr mutation in natural populations of Aedes albopictus from Brazil. Parasit Vectors. 2017;10(1):160. https://doi.org/10.1186/s13071-017-2089-5 PMID: 28347326

15. Chen H, Li K, Wang X, Yang X, Lin Y, Cai F, et al. First identification of kdr allele F1534S in VGSC gene and its association with resistance to pyrethroid insecticides in Aedes albopictus populations from Haikou City, Hainan Island, China. Infect Dis Poverty. 2016;5(1):31. https://doi.org/10.1186/ S40249-016-0125-X PMID: 27133234

16. Pichler V, Bellini R, Veronesi R, Arnoldi D, Rizzoli A, Lia RP, et al. First evidence of resistance to pyrethroid insecticides in Italian Aedes albopictus populations 26 years after invasion. Pest Manag Sci. 2018;74(6):1319-27. https://doi.org/10.1002/ ps.4840 PMID: 29278457

17. Kasai S, Komagata O, Itokawa K, Shono T, Ng LC, Kobayashi M, et al. Mechanisms of pyrethroid resistance in the dengue mosquito vector, Aedes aegypti: target site insensitivity, penetration, and metabolism. PLoS Negl Trop Dis. 2014;8(6):e2948. https://doi.org/10.1371/journal. pntd.0002948 PMID: 24945250

18. Finney DJ. Probit analysis 3rd ed. Cambridge: University Press; 1971

19. World Health Organization (WHO). Test procedures for insecticide resistance monitoring in malaria vector mosquitoes. 2nd ed. Geneva: WHO; 2016.

20. Rudbeck L, Dissing J. Rapid, simple alkaline extraction of human genomic DNA from whole blood, buccal epithelial cells, semen and forensic stains for PCR. Biotechniques. 1998;25(4):588-90, 592. https://doi.org/10.2144/98254bmog PMID: 9793639

21. Davies TGE, Field LM, Usherwood PNR, Williamson MS. A comparative study of voltage-gated sodium channels in the 
Insecta: implications for pyrethroid resistance in Anopheline and other Neopteran species. Insect Mol Biol. 2007;16(3):361 75. https://doi.org/10.1111/j.1365-2583.2007.00733.x PMID: 17433068

22. Folmer O, Black M, Hoeh W, Lutz R, Vrijenhoek R. DNA primers for amplification of mitochondrial cytochrome $c$ oxidase subunit I from diverse metazoan invertebrates. Mol Mar Biol Biotechnol. 1994;3(5):294-9. PMID: 7881515

23. Liu Z, Song W, Dong K. Persistent tetrodotoxin-sensitive sodium current resulting from U-to-C RNA editing of an insect sodium channel. Proc Natl Acad Sci USA. 2004;101(32):11862-7. https://doi.org/10.1073/pnas.0307695101 PMID: 15280550

24. Smith CE. The history of dengue in tropical Asia and its probable relationship to the mosquito Aedes aegypti. J Trop Med Hyg. 1956;59(10):243-51. PMID: 13368255

25. Benedict MQ, Levine RS, Hawley WA, Lounibos LP. Spread of the tiger: global risk of invasion by the mosquito Aedes albopictus. Vector Borne Zoonotic Dis. 2007;7(1):76-85. https://doi.org/10.1089/vbz.2006.0562 PMID: 17417960

26. Rezza G, Nicoletti L, Angelini R, Romi R, Finarelli AC, Panning $M$, et al. . Infection with chikungunya virus in Italy: an outbreak in a temperate region. Lancet. 2007;370(9602):18406. https://doi.org/10.1016/S0140-6736(07)61779-6 PMID: 18061059

27. Manica M, Cobre P, Rosà R, Caputo B. Not in my backyard: effectiveness of outdoor residual spraying from hand-held sprayers against the mosquito Aedes albopictus in Rome, Italy. Pest Manag Sci. 2017;73(1):138-45. https://doi.org/10.1002/ ps.4315 PMID: 27174441

28. Williamson MS, Martinez-Torres D, Hick CA, Devonshire AL. Identification of mutations in the housefly para-type sodium channel gene associated with knockdown resistance $(\mathrm{kdr})$ to pyrethroid insecticides. Mol Gen Genet. 1996;252(1-2):51-60. https://doi.org/10.1007/BF02173204 PMID: 8804403

29. Kasai S, Sun H, Scott JG. Diversity of knockdown resistance alleles in a single house fly population facilitates adaptation to pyrethroid insecticides. Insect Mol Biol. 2017;26(1):13-24. https://doi.org/10.1111/imb.12267 PMID: 27792261

30. Tsetsarkin KA, Vanlandingham DL, McGee CE, Higgs S. A single mutation in chikungunya virus affects vector specificity and epidemic potential. PLoS Pathog. 2007;3(12):e201. https://doi. org/10.1371/journal.ppat.0030201 PMID: 18069894

31. Succo T, Leparc-Goffart I, Ferré JB, Roiz D, Broche B, Maquart M, et al. Autochthonous dengue outbreak in Nîmes, South of France, July to September 2015. Euro Surveill. 2016;21(21):30240. https://doi.org/10.2807/1560-7917. ES.2016.21.21.30240 PMID: 27254729

32. Gjenero-Margan I, Aleraj B, Krajcar D, Lesnikar V, Klobučar A, Pem-Novosel I, et al. Autochthonous dengue fever in Croatia, August-September 2010. Euro Surveill. 2011;16(9):19805. PMID: 21392489

33. Sang S, Gu S, Bi P, Yang W, Yang Z, Xu L, et al. Predicting unprecedented dengue outbreak using imported cases and climatic factors in Guangzhou, 2014. PLoS Negl Trop Dis. 2015;9(5):e0003808. https://doi.org/10.1371/journal. pntd.0003808 PMID: 26020627

34. Kutsuna S, Kato Y, Moi ML, Kotaki A, Ota M, Shinohara K, et al. Autochthonous dengue fever, Tokyo, Japan, 2014.

Emerg Infect Dis. 2015;21(3):517-20. https://doi.org/10.3201/ eid2103.141662 PMID: 25695200

35. Sun H, Kasai S, Scott JG. Two novel house fly Vssc mutations, D600N and T929l, give rise to new insecticide resistance alleles. Pestic Biochem Physiol. 2017;143:116-21. https://doi. org/10.1016/j.pestbp.2017.08.013 PMID: 29183579

\section{License and copyright}

This is an open-access article distributed under the terms of the Creative Commons Attribution (CC BY 4.0) Licence. You may share and adapt the material, but must give appropriate credit to the source, provide a link to the licence, and indicate if changes were made.

This article is copyright of the authors or their affiliated institutions, 2019. 